\title{
AOR
}

Selected Papers of \#AolR2018:

The $19^{\text {th }}$ Annual Conference of the

Association of Internet Researchers

Montréal, Canada / 10-13 October 2018

\section{PURSUANCE AND THE PRACTICE OF DE-INSTITUTIONALIZED DEMOCRACY}

\author{
Robert Tynes \\ Bard College \\ Claire Peters \\ The Pursuance Project
}

The Internet enables people to more effectively organize for the achievement of civic, social and political goals outside the conventional housing of a formal institution. In digital spaces, people can collaborate and communicate closely even if they have never met in real life (Shirky 2009). Formations such as Telecomix and Project PM show that this capability can be harnessed in the service of meaningful collective political and social actions. Journalist and activist Barrett Brown's latest venture, a secure networking and organizing platform called Pursuance, hopes to further that potential. Pursuance provides a means for individuals to rapidly and effectively assemble, disassemble, and reassemble into mission-driven teams. This lessens the need for formal institutions to direct civic or political activism, thus opening a plethora of possibilities for the future of civil organizing. Nevertheless, we consider whether some form of "political organization and institutionalization to be not only still necessary but even greater than before" ( $p$. 20, Hardt and Negri 2017). In this light, we explore the potential of Brown's endeavor, asking: How can Pursuance most effectively further the practice of deinstitutionalized democracy? What can be learned from past groups that have engaged in the kind of activity Pursuance aims to facilitate?

Pursuance is an in-development platform that combines the functions of social networking and task management to empower agile activism. Its founder, Barrett Brown, first envisioned it as a platform that would mirror the shape of digital activist communities such as Anonymous. Anonymous, which is characterized by "a loose and decentralized command structure that operates on ideas rather than directives" (Owen 2015), demonstrated that political activism without institutions is possible (see Coleman 2014). Anonymous is more of a flag than a cohesive movement - different groups loosely related by a common Internet culture use the name as a call to coordinated action against large institutions perceived as abusive. Inspired by these dynamics, Brown founded Project PM, a digital research collaborative which most notably 
published emails from HBGary, a computer security firm that Anonymous had hacked in 2011. Project PM was an initiative that had no center, and was propelled by anonymous contributors. One goal was to make the intelligence contracting industry more transparent - and it succeeded.

Pursuance aims to take digital movements a step further by providing functionalities that are attuned to their dynamics. The result, if successful, is the creation of De Lagasnerie's (2017) "new political category" of individuals who are "not defined by their membership in a state, or a nation, or a territory, but rather belong to a community they have chosen for themselves: democracy" (89). That is, democracy unfettered, unbounded by the state - what Barrett Brown calls "process democracy." On the platform, a participant will be able to create a group focused on the achievement of a given goal, or search for and join one that aligns with their interests. The platform's groups will have both chat and task management components which can be either visible to others who might want to work with the project or encrypted end-to-end. The platform aims to effectively balance the need for both security and collaboration among emergent organizations, especially those with a political agenda.

Pursuance is meant to enable many different kinds of organizational models. Setting a long-term or aspirational goal, such as reversing the privatization of American prisons, is in line with more traditional forms of organization found in civic organizations and nonprofits; setting a substantive short-term goal, such as analyzing documents received through a set of Freedom of Information Act requests, encourages the kind of initiativedriven organizational instances that make groups like Anonymous so interesting. A pursuance is customizable in accordance with the needs of the group running it - it can be completely lateral and transparent, or require permissions for different levels.

Pursuance's vision is an ambitious one. It is conceived as a tool which will enable a paradigm shift in the way people organize. Its ability to make this vision a reality will be determined by how precisely it addresses the immediate needs of its users - how intuitively activists and journalists can use it - as well as how accurately it parses the dynamics it aims to enable. Our study analyzes the way Pursuance models the activities and ideals of its intended user base and compares it to the activities of the net-based activist groups that serve as its inspiration (e.g. Project PM, Anonymous, Telecomix). Through this analysis, we intend to discern to what extent Pursuance might fulfill its vision of "process democracy" and what additional steps might be needed to get it there.

We interview both central and periphery members of all three organizations to understand the range of experiences in digital activist collaborations. We also examine the planned structure of the platform, through interviews with the creator, Barrett Brown, and the developers building Pursuance (Steve Phillips et al.). We then compare the experiences of digital activists to Pursuance's envisioned structure, examining where Pursuance will augment the digital activist's experience - how it will harness the revolutionary aspects of online activism and minimize the issues that can arise. We also note where the platform has the potential to fall short, and recommend appropriate countermeasures based on our research. 
Some of the problems we will explore include: whether Pursuance presents a new episteme or merely replicates state ideology (Althusser 2014; Bourdieu 2015; Gramsci 1971); how the mystification of "no hierarchy" can produce talk but little action, what Freeman (1970) labels, "political impotence"; and the potential for infiltration and sabotage of the Project altogether (see the case of Sabu and LulzSec, Coleman 2014).

\section{References}

Althusser, Louis (2014) On The Reproduction Of Capitalism: Ideology And Ideological State Apparatuses. New York: Verso.

Bourdieu, Pierre (2015). On the State. Cambridge, UK: Polity Press.

Brown, Barrett (2018). The Pursuance Project. Available at: https://pursuanceproject.org

Coleman, Gabriella. 2014. Hacker, Hoaxer, Whistleblower, Spy: The Many Faces of Anonymous. London, UK: Verso.

De Lagasnerie, Geoffroy (2017). The Art of Revolt. Stanford: Stanford University Press.

Freeman, Jo (1970). "The Tyranny of Structurelessness." Available at:

http://www.jofreeman.com/joreen/tyranny.htm

Gramsci, Antonio (1971), Selections from the Prison Notebooks. New York: International Publishers Co.

Hardt, Michael and Antonio Negri (2017). Assembly. Oxford: Oxford University Press.

Michels, Robert (1915). Political Parties: A Sociological Study of the Oligarchical Tendencies of Modern Democracy. Translated into English by Eden Paul and Cedar Paul. New York: The Free Press.

Owen, Taylor (2015). Disruptive Power: The Crisis of the State in the Digital Age. Oxford: Oxford University Press.

Shirky, Clay (2009). Here Comes Everybody: The Power of Organizing Without Organizations. New York: Penguin Books. 